\title{
Toxicity of Insecticide-Contaminated Soil Used in the Treatment of Cotton Seeds to Bees
}

\author{
Ellen P. de Souza ${ }^{1}$, Paulo E. Degrande ${ }^{2}$, Rosalia Azambuja ${ }^{1}$, Rafael A. da Silva ${ }^{3}$ \& Valter V. Alves Junior ${ }^{1}$ \\ ${ }^{1}$ Faculdade de Ciências Biológicas e Ambientais, Universidade Federal da Grande Dourados, Dourados, MS, \\ Brazil \\ ${ }^{2}$ Faculdade de Ciências Agrárias, Universidade Federal da Grande Dourados, Dourados, MS, Brazil \\ ${ }^{3}$ Instituto Federal de Mato Grosso do Sul, Nova Andradina, MS, Brazil \\ Correspondence: Ellen P. de Souza, Faculdade de Ciências Biológicas e Ambientais, Universidade Federal da \\ Grande Dourados, Rodovia Dourados/Itahum, Km 12, Caixa Postal 533, CEP: 79.804-970, Dourados, MS, \\ Brazil. Tel: 55-67-996-982-099. E-mail: ellen_psouza@hotmail.com
}

Received: June 7, 2018

doi:10.5539/jas.v10n10p189
Accepted: July 20, $2018 \quad$ Online Published: September 15, 2018

URL: https://doi.org/10.5539/jas.v10n10p189

\begin{abstract}
Insecticide-treated cotton seeds can pose risks to Apis mellifera Linnaeus, 1758 populations during crop establishment if chemical residues reach these insects near agricultural fields via dust drift produced during planting. However, the treatment of seeds with insecticides is essential to protect cotton plants from damage caused by pests, including thrips and aphids. Thus, the aim of this study was to evaluate the toxic effects (acute toxicity) of soil dust from cotton fields planted with insecticide-treated seeds on A. mellifera adults using a toxicity assay developed in the laboratory. Forager honeybees were maintained in $700-\mathrm{ml}$ plastic cages with $7 \mathrm{~g}$ of surface soil where insecticide-treated cotton seeds were sown ( $270 \mathrm{~g}$ a.i. clothianidin, $270 \mathrm{~g}$ a.i. imidacloprid, $210 \mathrm{~g}$ a.i. thiamethoxam, and $75 \mathrm{~g}$ a.i. fipronil $/ 100 \mathrm{~kg}$ of seeds, and an untreated group). Ten bees were placed in each cage. The experimental design was randomized, with five treatments and twelve replicates. The mortality rate was evaluated during the entire assay. Data were transformed to $\sqrt{\mathrm{x}+0.5}$ and compared with a regression analysis and contrast test. The linear regression model revealed a significant relationship between bee mortality and exposure time. The mortality rate gradually increased as time progressed in all treatments and the control group. The contrast test did not reveal significant differences between the insecticide and control groups. Thus, residues of the products tested, thiamethoxam, clothianidin, imidacloprid, and fipronil, did not influence the mortality of $A$. mellifera adults as a result of exposure to soil contaminated with insecticide-treated seeds.
\end{abstract}

Keywords: Apis mellifera, cotton, fipronil, neonicotinoid, side effects

\section{Introduction}

Cotton is widely used by industries worldwide and is a fundamental commodity to the primary and secondary sectors. The global area of cotton crops was estimated at 33.9 million ha in 2014-2015 and 30.92 million ha in 2015-2016, while world production reached $763 \mathrm{~kg} / \mathrm{ha}(2014-2015)$ and $701 \mathrm{~kg} / \mathrm{ha}$ (2015-2016) according to the USDA (2016).

One of the yield-limiting factors is insect pests, requiring the use of chemical insecticides. Neonicotinoids efficiently control the main pests of cotton, such as the boll weevil, Anthonomus grandis Boheman 1843 (Fonseca et al., 2011), aphids, thrips, and whiteflies (Torres et al., 2004; Andrei, 2013). However, these insecticides may affect important beneficial insects for this crop, such as pollinators.

The neonicotinoids, clothianidin, imidacloprid, thiamethoxam, and fipronil have been considered potential factors associated with Colony Collapse Disorder (CCD), characterized by the sudden disappearance of worker bees and weakening of colonies. Nonetheless, it is unclear if a single factor is consistently or sufficiently abundant in CCD-affected colonies to be identified as the causative agent (van Engelsdorp et al., 2009).

The presence of pollinators, especially the Africanized bee, in cotton fields, has been associated with increased production (Sanchez-Junior \& Marlebo-Souza, 2004). Although the number of bolls may not increase, higher numbers of seeds per fruit have been reported. Thus, information on lethal and sub-lethal effects of insecticides on beneficial insects, such as behavioral and physiological alterations, when applied to crops to control pests 
during the stages of flowering and young bolls, is essential to obtain the maximum benefits of pollination by bees (Freitas \& Pinheiro, 2010; Pinheiro \& Freitas, 2010).

Bees that inhabit and feed near agricultural fields are exposed to several pesticides in many ways. One of them is the dust generated during planting, contaminated with residues of insecticides used to treat seeds. The highest levels of exposure and concentration occur during planting and the danger of these pesticides to bees is the result of exposure and toxicity. Exposure duration and developmental stage are also important factors affecting the potential toxicity to bees (Chauzat et al., 2006; Krupke et al., 2012).

Krupke et al. (2012) reported the presence of pesticides, such as clothianidin, on the agricultural soil surface where treated seeds were planted, and in some cases, where treated seeds were not sown. In addition, the dust that rises during planting can settle on flowers visited by bees, or even on insects.

Concerns have been raised over the high levels of clothianidin, imidacloprid, thiamethoxam, and fipronil used to treat seeds that can be released into the environment during and after sowing. As a result, large areas planted with treated seeds combined with the high persistence of pesticide residues and soil mobility might have negative effects on beneficial organisms, including plants near agricultural fields (Krupke et al., 2012).

Since these pesticides could be associated with CCD, and residues have been found in the soil, the aim of the present study was to evaluate the effects of insecticide-contaminated soil collected near where treated seeds were sown on A. mellifera bees, by developing a laboratory bioassay based on bee mortality to evaluate insecticide residue in the soil after sowing.

\section{Material and Methods}

The study was conducted at the Laboratory of Applied Entomology at the School of Agricultural Sciences (Faculdade de Ciências Agrárias-FCA) of the Federal University of Grande Dourados (Universidade Federal da Grande Dourados-UFGD), in Dourados, Mato Grosso do Sul, Brazil.

Bees used in the experiment were collected directly from the entrance of beehives maintained at the UFGD experimental farm, at approximately 7:00 am, when bees were leaving the hive to forage. Preliminary tests indicated that this was the most appropriate period to handle bees for the assays.

\subsection{Collecting Containers, Transportation, and Transfer to Cages}

A bioassay was developed to evaluate the toxicity of insecticides and residues to A. mellifera in the laboratory. For the bioassay a container was designed using plastic (polypropylene) materials found in stores (Patented: Process Number: BR 102018010112 9). The bottoms of 2-L plastic bottles were removed to allow bees to enter. The lid was altered by attaching the neck of a spray bottle to allow the transfer of bees to exposure cages. This portion of the container was cut and a plastic barrier was placed to control the number of bees exiting the container (Figure 1).

During the experiments, modifications to the containers were required. Perforations were made to increase ventilation inside the collecting container, and instead of an opening at the bottom of the bottle to collect bees, a lateral opening was made. This opening was closed with cotton to prevent bees from escaping during transportation to the laboratory (Figure 1). 


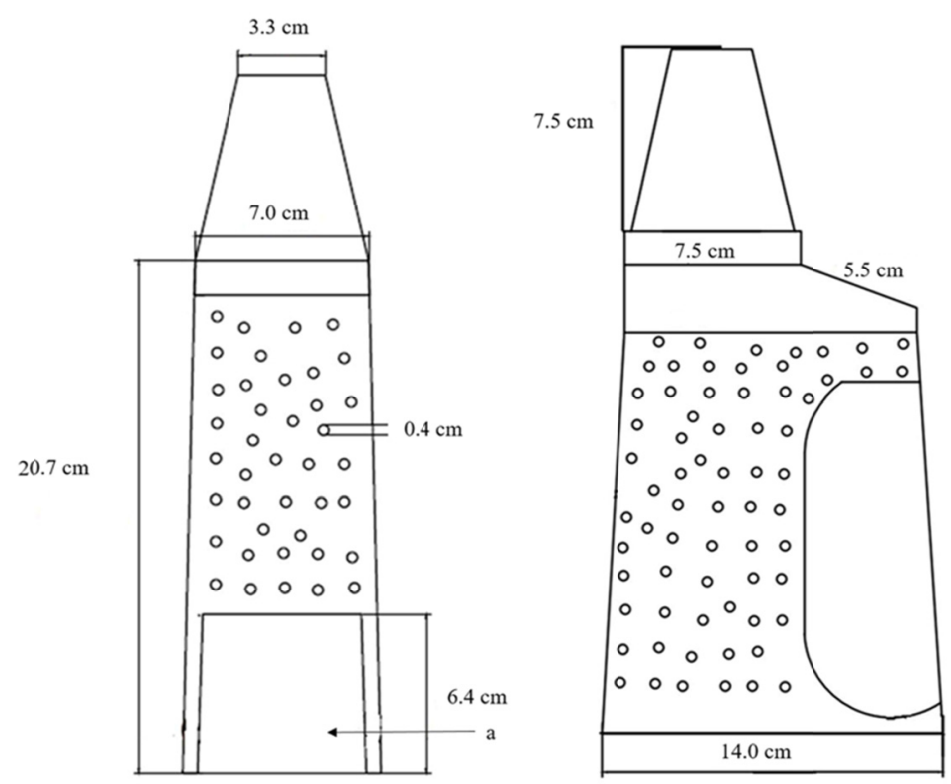

Figure 1. Container used to collect, transport to laboratory, and transfer A. mellifera bees to cage tests (a: opening to allow bees to enter the container)

\subsection{Exposure Cages}

For the development of exposure cages, we initially tested 300-ml plastic containers with lids. Holes of $3.5 \mathrm{~cm}$ in diameter were cut in the center of the containers to allow the entrance of bees and foam was used as a lid. Small perforations were made in the lid; however, they did not provide adequate ventilation in the cage.

We then tested 2-L glass Erlenmeyer flasks covered with mesh fabric and 500-ml plastic cups. In Erlenmeyer flasks, bees survived for longer periods; nonetheless, the mouth of the flasks was wider than that of the container used to transfer bees, making this procedure difficult and allowing some bees to escape. In addition, ventilation could not be improved; hence, the use of Erlenmeyer flasks was discontinued. Compared to 300-ml plastic containers, 500-ml bottles were more appropriate, as they were larger, but bee mortality before exposure to contaminated soil was still an issue.

Contamination of the 500-ml containers prior to assays was suspected, since mortality of bees was observed without exposure to contaminated soil, including bees in the control group. Therefore, after several attempts, containers and suppliers were changed and the size of the cage and ventilation were increased.

The final experimental apparatus consisted of 700-ml plastic (Polystyrene) cups with lids, with two entrances on the sides covered with mesh fabric (Figure 2) (Patented: Process Number: BR 102018010112 9). A round opening was made in each lid to transfer bees from the collecting container to the exposure cages and closed with cotton moistened in a $20 \%$ honey water solution. 


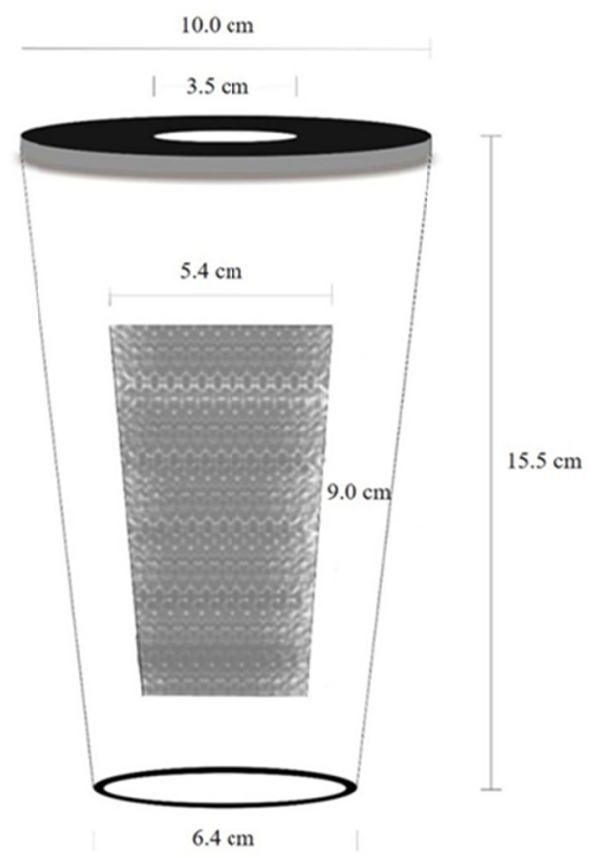

Figure 2. Plastic cups with openings on sides covered with screen fabric used as cages for exposure of A. mellifera bees to contaminated soil showing details of the entrance of bees into the container

\subsection{Exposure Tests}

Forager workers older than 21 days (Free, 1980), the ones most exposed to field conditions, were collected from the hive entrance and transported to the laboratory. Ten bees were transferred to each exposure cage. To ensure bees within replicates were of a similar age, bees from the same container were used.

Five NuOpal Bollgard cotton seeds treated with chemical insecticides were sown in 15-L pots filled with substrate, fertilizer, and lime. According to the manufacturer, insecticide concentrations were as follows: clothianidin (Poncho ${ }^{\circledR} 600 \mathrm{SC}$ ) at $270 \mathrm{~g}$ a.i. $/ 100 \mathrm{~kg}$ of seeds, imidacloprid $\left(\right.$ Gaucho ${ }^{\circledR} 600 \mathrm{FS}$ ) at $270 \mathrm{~g}$ a.i. $/ 100 \mathrm{~kg}$ of seeds, thiamethoxam (Cruiser ${ }^{\circledR} 350 \mathrm{FS}$ ) at $210 \mathrm{~g}$ a.i. $/ 100 \mathrm{~kg}$ of seeds, and fipronil (Standak ${ }^{\circledR} 250 \mathrm{SC}$ ) at $75 \mathrm{~g}$ a.i./100 kg of seeds. The control group contained untreated seeds.

On the same day that the sowing occurred, surface soil from the site where each seed was sown was collected. Then $7 \mathrm{~g}$ of soil in permanent wilting point were weighed and placed in each exposure cage with bees. One hour after exposure, the first evaluation was carried out, following which the interval between evaluations gradually increased until $16 \mathrm{~h}$ after exposure $(1,2,4,8,16 \mathrm{~h})$. During evaluation, bees were considered dead when they remained immobile after providing mechanical stimuli in the exposure cage.

The experimental design was randomized and consisted of five treatments (insecticides and control) with 12 replicates each, and 10 individuals per replicate, totaling 120 bees per treatment.

\subsection{Statistical Analysis}

As the data did not meet the assumption of normality, they were transformed to $\sqrt{\mathrm{x}+0.5}$ and analyzed with a linear regression and the Scheffé's contrast test performed with the statistical software, SISVAR.

\section{Results}

A novel method was developed for the collection, transportation, and transfer of bees, as described in Material and Methods (Patent: Process Number: BR 102018010112 9).

\subsection{Exposure Tests}

The regression analysis revealed a significant relationship between bee mortality and time of exposure for all treatments and the control group (clothianidin $\mathrm{r}^{2}=0.9403$, imidacloprid $\mathrm{r}^{2}=0.9193$, thiamethoxam $\mathrm{r}^{2}=0.921$, fipronil $\mathrm{r}^{2}=0.9177$, control $\mathrm{r}^{2}=0.9804$ ). Mortality gradually increased over exposure time to insecticidecontaminated soil but was not statistically different from that of the control treatment (Figure 3, Table 1). 
Table 1. Analysis of variance of mortality of A. mellifera bees after exposure to soil contaminated with treated cotton seeds

\begin{tabular}{llllll}
\hline \multirow{2}{*}{ FV } & \multicolumn{5}{c}{ Mean square } \\
\cline { 2 - 6 } & TC & TI & TH & TF & TT \\
\hline Treated & $140.541^{* *}$ & $108.858^{* *}$ & $146.958^{* *}$ & $110.316^{* *}$ & $98.683^{* *}$ \\
Residue & 2.287 & 1.649 & 1.940 & 1.325 & 1.883 \\
\hline CV $(\%)$ & 22.61 & 18.50 & 19.00 & 14.86 & 22.54 \\
\hline
\end{tabular}

Note. ${ }^{* *}$ Significant at $5 \%$ level. Data transformed to $\sqrt{\mathrm{x}+0.5} . \mathrm{CV}=$ coefficient of variation. $\mathrm{TC}=$ treatment with clothianidin, $\mathrm{TI}=$ treatment with imidacloprid, $\mathrm{TH}=$ treatment with thiamethoxam, $\mathrm{TF}=$ treatment with fipronil, and $\mathrm{TT}=$ control (no insecticide).

Similar results were observed for the control group, indicating a natural mortality rate throughout the exposure time under the experimental conditions that the bees were subjected to, with a mean of seven dead bees at the end of the experiment (Figure 3). No significant differences were found with the contrast analysis between the mean of the treatment groups and that of the control group, with an overall mean mortality of 3.59. Despite the high toxicity of the tested neonicotinoids and fipronil to A. mellifera, these insecticides did not increase the mortality of bees exposed to soil in the place where treated cotton seeds were sown. The quantity of residues in the soil might have been insufficient to cause mortality. However, a high mortality rate was obtained for the control group at the end of the evaluations, which may have been caused by the pesticide-free dust formed in the exposure cage at the time the bees were exposed to the soil. The quantity of insecticide residues from treated seeds during sowing is an important factor, since even highly toxic compounds to A. mellifera did not increase bee mortality in the tests conducted in our study. 

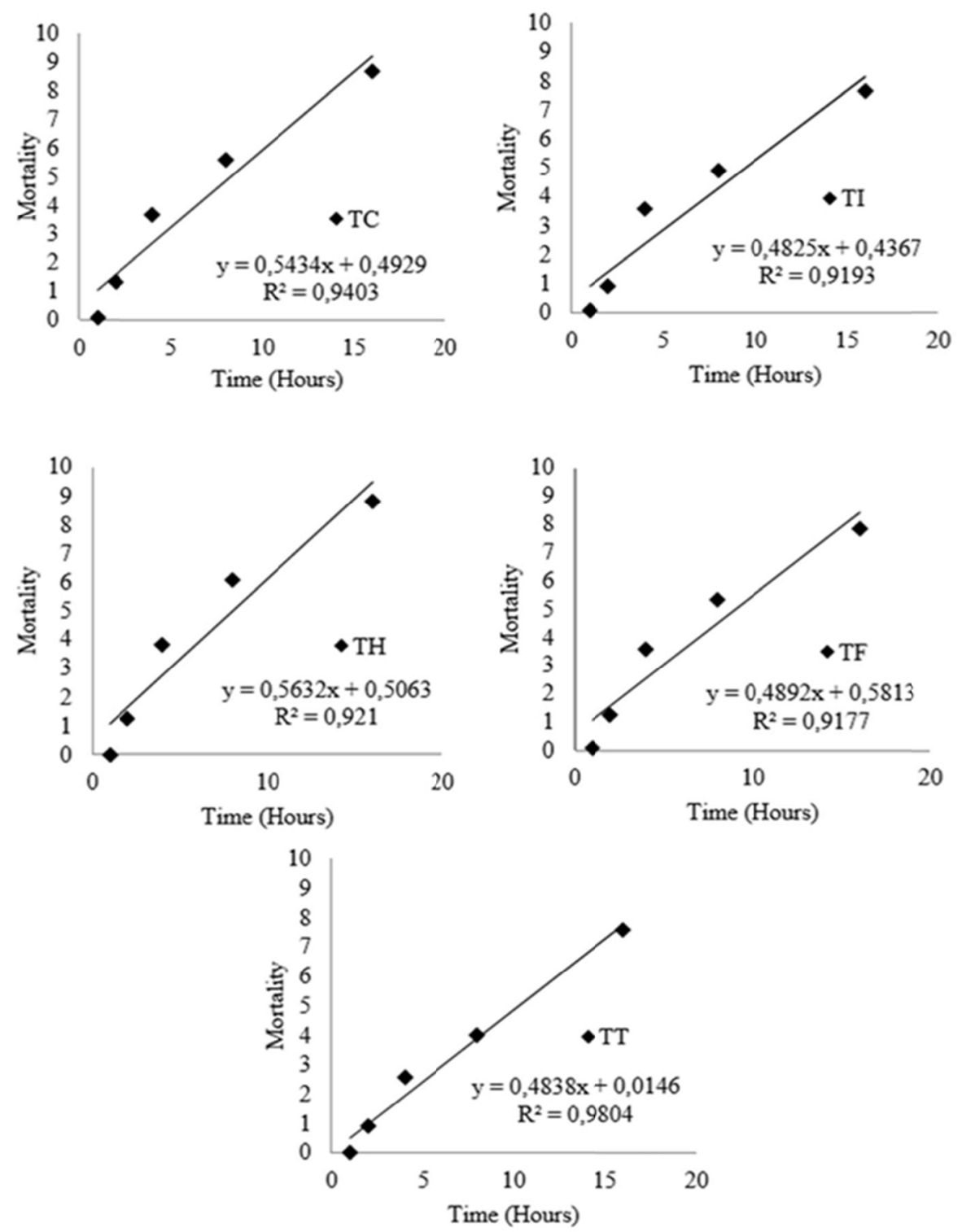

Figure 3. Linear regression of exposure of $A$. mellifera bees to soil contaminated with seeds treated with clothianidin (TC), imidacloprid (TI), thiamethoxam (TH), and fipronil (TF), and control (TT) group

\section{Discussion}

Despite the high toxicity to bees of the insecticides examined in this study, when adults were exposed to soil collected near where treated seeds were planted, no adverse effects were observed to bees. This was also found for the insecticide thiamethoxam, considered extremely toxic to honeybees via ingestion of contaminated food, spraying, or contact with treated surfaces, with $100 \%$ mortality rates reported within $9 \mathrm{~h}$ of direct exposure (Carvalho et al., 2009). Thiamethoxam is not selective to A. mellifera adults and bee mortality exposed to plants sprayed with this insecticide can reach $100 \%$ in $5 \mathrm{~h}$ and $30 \mathrm{~min}$ after the initial exposure (Thomazoni et al., 2009). However, in the method of exposure used in our study, mortality was higher $16 \mathrm{~h}$ after initial exposure, although not statistically different from the control group.

Williamson et al. (2014) evaluated the mortality of adult bees fed 10 and $100 \mathrm{nM}$ of thiamethoxam, clothianidin, dinotefuran, imidacloprid, and nicotine in a sucrose solution during a period of $24 \mathrm{~h}$. These authors determined sub-lethal doses in behavioral experiments and observed that at the concentration of $100 \mathrm{nM}$, mortality significantly increased compared to that of the control group. Jacob et al. (2013) examined the effects of fipronil and obtained a lethal dose and concentration of $0.54 \mathrm{ng} / \mathrm{bee}$ and $0.24 \mathrm{ng} / \mu \mathrm{L}$ of diet after $24 \mathrm{~h}$, respectively, for newly emerged stingless bee workers of Scaptotrigona postica Latreille, 1807. The authors considered these 
values highly toxic to these bees. However, Roat et al. (2013) determined an LD50 and LC50 of $1.07 \mathrm{ng} / \mathrm{bee}$ and $1.27 \mathrm{ng} / \mathrm{ml}$ of diet for newly emerged A. mellifera bees, suggesting a higher resistance of these bees to fipronil, since both have similar habits.

The insecticides imidacloprid and clothianidin added to the diet can cause behavioral changes in honeybees, reducing their flight capacity, causing immobility, trembling, and arched abdomens (Bortolotti et al., 2003; Schneider et al., 2012). A. mellifera bees exposed to 0.5 and $1 \mathrm{ng}$ of clothianidin had their ability to return to the food source reduced by 31 and $71 \%$, respectively. The ingestion of 1.5 and $3 \mathrm{ng}$ of imidacloprid with food reduced this ability by 47 and $98 \%$, respectively (Schneider et al., 2012). High mortality rates have been reported for honeybees exposed to surfaces or food contaminated with clothianidin and thiamethoxam, as well as other insecticides. At high doses, their effects can be observed on bees within the first hour after exposure (Laurino et al., 2011). In fact, neonicotinoids are known to be highly toxic to A. mellifera bees when they are exposed to contaminated diets, which causes a high mortality rate as well as negative effects on their motor capacity. However in our study the seed treatment in wettable powder was a safe way to employ insecticides to control pests while minimizing the risks to $A$. mellifera.

Despite the high toxicity of these insecticides to honeybees, when used in the treatment of cotton seeds, they had a low impact on bee mortality rates under laboratory conditions. Thus, in the present study, exposure to soil planted with chemically treated seeds did not affect bee mortality and the observed mortality throughout the treatment possibly reflected natural rates, as the quantity of residues of insecticides may have been insufficient to result in bee mortality.

Our findings suggest that the wet method used to treat seeds may decrease the quantity of residues transferred to the soil from seeds, and consequently the direct contact with bees. Technological innovations in seed treatment, such as better adherence of the product to seeds and improvements in planting and seeding equipment to increase soil cover over the seed, may further decrease insecticide residues from seeds to the soil, minimizing the risks of chemical exposure, despite its high toxicity.

The mortality rate observed in the control group without insecticide during this experiment might have occurred due to the dust formed inside the cage concomitant with the stress of handling and transporting bees, leading to higher rates than usual. Further studies should be conducted to investigate the effect of pesticide-free dust on bee survival.

\section{Conclusions}

This study showed that the pesticides thiamethoxam, clothianidin, imidacloprid, and fipronil did not influence the mortality of A. mellifera bees in direct contact with soil collected near where treated seeds were sown and that this seed treatment was considered of low risk to bees.

\section{References}

Andrei, E. (2013). Compêndio de defensivos agrícolas: Guia prático de produtos fitossanitários para uso agrícola (9th ed.). São Paulo: Organização Andrei.

Bortolotti, L., Montanari, R., Marcelino, J., Medrzycki, P., Maini, S., \& Porrini, C. (2003). Effects of sub-lethal imidacloprid doses on the homing rate and foraging activity of honey bees. Bulletin of Insectology, 56, 63-67.

Carvalho, S. M., Carvalho, G. A., Carvalho, C. F., Bueno Filho, J. S. S., \& Baptista, A. P. M. (2009). Toxicidade de acaricidas/inseticidas empregados na citricultura para a abelha africanizada Apis mellifera L., 1758 (Hymenoptera: Apidae). Arquivos do Instituto Biológico, 76(4), 597-606.

Chauzat, M. P., Faucon, J. P., Martel, A. C., Lachaize, J., Cougoule, N., \& Aubert, M. (2006). A survey of pesticide residues in pollen loads collected by honey bees in France. Journal of Economic Entomology, 99(2), 253-262. https://doi.org/10.1603/0022-0493-99.2.253

Fonseca, P. R. B., Lima Junior, I. S., Soria, M. F., Kodama, C., \& Degrande, P. E. (2011). Inseticidas neonicotinóides no controle do bicudo-do-algodoeiro Anthonomus grandis (Boheman, 1843) (Coleoptera: Curculionidae) e a falha de controle do endosulfan. Arquivos do Instituto Biológico, 78(4), 545-551.

Free, J. B. (1980). A organização social das abelhas (Apis) (p. 79). São Paulo, SP: EPU.

Freitas, B. M., \& Pinheiro, J. N. (2010). Efeitos sub-letais dos pesticidas agrícolas e seus impactos no manejo de polinizadores dos agroecossistemas brasileiros. Oecologia Australis, 14(1), 282-298. https://doi.org/ $10.4257 /$ oeco.2010.1401.17 
Jacob, C. R. O., Soares, M. H., Carvalho, S. M., Nocelli, R. C. F., \& Malaspina, O. (2013). Acute toxicity of fipronil to the stingless bee Scaptotrigona postica Latreille. Bulletin of Environmental Contamination and Toxicology, 72, 90-96. https://doi.org/10.1007/s00128-012-0892-4

Krupe, C. H., Hunt, G. J., Eitzer, B. D., Andino, G., \& Given, K. (2012). Multiple routes of pesticide exposure for honey bees living near agricultural fields. PLoS One, 7(1), e29268. https://doi.org/10.1371/journal. pone. 0029268

Laurino, D., Porporato, M., Patetta, A., \& Manino, A. (2011). Toxicity of neonicotinoid insecticides to honey bees: laboratory tests. Bulletin of Insectology, 64(1), 107-113.

Pinheiro, J. N., \& Freitas, B. M. (2010). Efeitos letais dos pesticidas agrícolas sobre polinizadores e perspectivas de manejo para os agroecossistemas brasileiros. Oecologia Australis, 14(1), 266-281. https://doi.org/ 10.4257/oeco.2010.1401.16

Roat, T. C., Carvalho, S. M., Nocelli, R. C. F., Silva-Zacarin, E. C. M., Palma, M. S., \& Malaspina, O. (2013). Effects of sublethal dose of fipronil on neuron metabolic activity of Africanized honeybees. Archives of Environmental Contamination and Toxicology, 64, 456-466. https://doi.org/10.1007/s00244-012-9849-1

Sanchez-Junior, J. L. B., \& Marlebo-Souza, D. T. (2004). Frequência dos insetos na polinização e produção do algodoeiro. Acta Scientiarum Agronomy, 26(4), 461-465. https://doi.org/10.4025/actasciagron.v26i4.1808

Schneider, C. W., Tautz, J. Grünewald, B., \& Fuchs, S. (2012). RFID Tracking of sublethal effects of two neonicotinoid insecticides on the foraging behavior of Apis mellifera. PLoS One, 7(1), e30023. https://doi.org/10.1371/journal.pone.0030023

Thomazoni, D., Soria, M. F., Kodama, C., Carbonari, V., Fortunato, R. P., Degrande, P. E., \& Valter-Alves, V. Jr. (2009). Selectivity of insecticides for adult workers of Apis mellifera (Hymenoptera: Apidae). Revista Colombiana de Entomología, 35(2), 173-176.

Torres, J. B., \& Ruberson, J. R. (2004). Toxicity of thiamethoxam and imidacloprid to Podisus nigrispinus (Dallas) (Heteroptera: Pentatomidae) nymphs associated to aphid and whitefly control in cotton. Neotropical Entomology, 33(1), 99-106. https://doi.org/10.1590/S1519-566X2004000100017

USDA (United States Department of Agriculture). (2016). Cotton: World Markets and Trade. Foreign Agricultural Service. Retrieved June 3, 2016, from http://apps.fas.usda.gov/psdonline/circulars/cotton.pdf

van Engelsdorp, D., Evans, J. D., Saegerman, C., Mullin, C., Haubruge, E., Nguyen, B. K., ... Pettis, J. S. (2009). Colony collapse disorder: A descriptive study. PLoS One, 4(8), e6481. https://doi.org/10.1371/journal. pone. 0006481

Williamson, S. M., Willis, S., \& Wright, G. A. (2014). Exposure to neonicotinoids influences the motor function of adult worker honeybees. Ecotoxicology, 23, 1409-1418. https://doi.org/10.1007/s10646-014-1283-x

\section{Copyrights}

Copyright for this article is retained by the author (s), with first publication rights granted to the journal.

This is an open-access article distributed under the terms and conditions of the Creative Commons Attribution license (http://creativecommons.org/licenses/by/4.0/). 